\title{
Increased training prevents the impairing effect of intra-amygdala infusion of the non-NMDA receptor antagonist CNQX on inhibitory avoidance expression
}

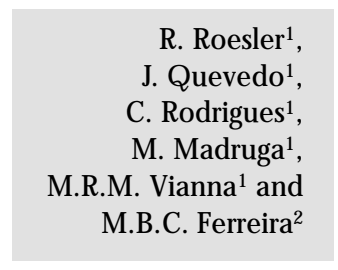

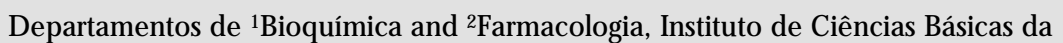
Saúde, Universidade Federal do Rio Grande do Sul, Porto Alegre, RS, Brasil

\section{Correspondence \\ R. Roesler \\ Departamento de Bioquímica ICBS, UFRGS \\ 90035-003 Porto Alegre, RS \\ Brasil \\ Fax: + 55-51-315-5535 \\ E-mail: quevedo@vortex.ufrgs.br}

Research supported by Programa de Núcleos de Excelência (PRONEX), CNPq, and UFRGS.

Received July 17, 1997 Accepted December 14, 1998

\begin{abstract}
Intra-amygdala infusion of the non-N-methyl-D-aspartate (NMDA) receptor antagonist 6-cyano-7-nitroquinoxaline-2,3-dione (CNQX) prior to testing impairs inhibitory avoidance retention test performance. Increased training attenuates the impairing effects of amygdala lesions and intra-amygdala infusions of CNQX. The objective of the present study was to determine the effects of additional training on the impairing effects of intra-amygdala CNQX on expression of the inhibitory avoidance task. Adult female Wistar rats bilaterally implanted with cannulae into the border between the central and the basolateral nuclei of the amygdala were submitted to a single session or to three training sessions ( $0.2 \mathrm{~mA}, 24-\mathrm{h}$ interval between sessions) in a step-down inhibitory avoidance task. A retention test session was held $48 \mathrm{~h}$ after the last training. Ten minutes prior to the retention test session, the animals received a $0.5-\mu l$ infusion of CNQX $(0.5 \mu \mathrm{g})$ or its vehicle ( $25 \%$ dimethylsulfoxide in saline). The CNQX infusion impaired, but did not block, retention test performance in animals submitted to a single training session. Additional training prevented the impairing effect of CNQX. The results suggest that amygdaloid non-NMDA receptors may not be critical for memory expression in animals given increased training.
\end{abstract}

Extensive evidence suggests that the amygdala is involved in aversively motivated memory. However, there has been controversy concerning the specific role of the amygdala in memory. One view is that the amygdala serves as a primary site of neural changes mediating acquisition and storage
Key words

- Amygdala

- Non-N M DA receptor

- Long-term potentiation

- Inhibitory avoidance

- Memory

- Fear of fear memory. Long-term potentiation (LTP) at glutamatergic synapses is the leading candidate as a neural plasticity mechanism that underlies memory processing by the amygdala (1-9). LTP induction depends on N-methyl-D-aspartate (NMDA) glutamate receptor channels, and expression of LTP 
depends on non-NMDA glutamate receptors (10). Infusions of NMDA receptor antagonists into the amygdala block retention of fear conditioning (2), fear-potentiated startle $(1,4)$ and inhibitory avoidance $(6,8,9,11)$. Furthermore, intra-amygdala infusions of the non-NMDA receptor antagonist 6-cyano-7nitroquinoxaline-2,3-dione (CNQX) prior to testing impair both inhibitory avoidance $(5,7,8)$ and fear-potentiated startle (3). These data are consistent with the view that the amygdala participates in the acquisition and storage of aversively motivated memory through LTP. Another view regarding the role of the amygdala in memory is that it is a modulatory site which regulates memory storage and/or consolidation in other brain regions (12). This view is supported by evidence that amygdaloid lesions do not block retention of inhibitory avoidance (13) or escape training responses (14). Furthermore, the findings that increased training attenuates the impairing effects of amygdaloid lesions (14) and of intra-amygdala infusions of CNQX given prior to the test (15) on escape training response support the view that the amygdala is a modulatory site rather than a critical storage site for memory. If the amygdala were a critical site for storage and retrieval, amygdaloid lesions and intra-amygdala infusions of CNQX would block memory regardless of the extent of original training $(14,15)$. Intra-amygdala infusion of CNQX prior to testing is known to impair retention of step-down inhibitory avoidance, a fearmotivated memory task $(5,7,8)$. To investigate the effects of increased training on intra-amygdala CNQX-induced memory impairment, we examined inhibitory avoidance retention in rats given additional training sessions and infused with CNQX into the amygdala prior to the retention test session.

Adult female Wistar rats (180-230 g) were housed 5 to a cage with free access to water and food, and maintained on a 12-h light-dark cycle (lights on at 7:00 a.m.) at a temperature of $23 \pm 1^{\circ} \mathrm{C}$. Behavioral proce- dures took place in the afternoon.

Animals were bilaterally implanted under thionembutal anesthesia $(30 \mathrm{mg} / \mathrm{kg}$, ip $)$ with guide cannulae aimed $1.0 \mathrm{~mm}$ above the border between the central and the basolateral nuclei of the amygdala (5-9). Stereotaxic coordinates were A -2.3, L 4.5, $\mathrm{V}-7.4$, according to the atlas of Paxinos and Watson (16).

Animals were submitted to a single training session or to three training sessions followed by a retention test session in a stepdown inhibitory avoidance task. For the animals submitted to a single training session, the training-test interval was $48 \mathrm{~h}$. In animals submitted to three training sessions, the interval between training sessions was $24 \mathrm{~h}$, and the interval between the third training session and the test session was $48 \mathrm{~h}$. The inhibitory avoidance apparatus was an automatically operated, brightly illuminated box as described elsewhere (5-9). The left end of the grid was covered with a $7.0-\mathrm{cm}$ wide, $2.5-\mathrm{cm}$ high formica platform. Animals were placed on the platform and their latency to step-down with the four paws on the grid (a $42.0 \times 25.0-\mathrm{cm}$ grid of parallel $0.1-\mathrm{cm}$ caliber stainless steel bars spaced $1.0 \mathrm{~cm}$ apart) was measured. In the training sessions, immediately after stepping down, the animals received a 0.2-mA, 2-s scrambled footshock. No footshock was given in the test sessions. A ceiling of $300 \mathrm{~s}$ was imposed on stepdown latencies. Thus, values equal to or higher than $300 \mathrm{~s}$ were counted as $300 \mathrm{~s}$. The interval between sessions was $24 \mathrm{~h}$. Ten minutes prior to the test session, a 30 -gauge injection cannula was fitted into the guide cannula, and animals were given a $0.5-\mu 1$ infusion of vehicle (25\% dimethylsulfoxide in saline) or CNQX $(5.0 \mu \mathrm{g})$ dissolved in the vehicle as previously described $(5,7,8)$.

After the retention test sessions, animals were sacrificed by decapitation, and cannula placements were verified post-mortem by histological examination as described elsewhere (5-9). Cannulae were found to be 
correctly placed $1.0 \mathrm{~mm}$ above the border between the central and the basolateral nuclei of the amygdala in 24 vehicle-treated rats and $20 \mathrm{CNQX}$-treated rats (data not show). Data from animals with misplaced cannulae were not included in the final analysis.

Data are reported as median (interquartile range) latency to step-down. In animals submitted to a single training session, training and test session latencies were compared by the Wilcoxon test. In animals submitted to three training sessions, enhancement of performance across consecutive sessions was analyzed by Friedman two-way analysis of variance, and the third training and test session latencies were compared by the Wilcoxon test. Comparisons between different groups were made by the Mann-Whitney test; $\mathrm{P}<0.05$ was considered to indicate statistical significance.

Results of the single-training experiment are shown in Table 1. There was no difference between groups in training session latencies ( $\mathrm{P}>0.10$, Mann-Whitney test). There was a significant difference between groups in test session latencies $(\mathrm{P}<0.05$, MannWhitney test), and there were significant differences between training and test session latencies in both vehicle and CNQX groups $(\mathrm{P}<0.05$, Wilcoxon test), indicating that intraamygdala CNQX attenuated, but did not completely block, inhibitory avoidance retention.
Table 1 - Median (interquartile range) of latencies to step-down of rats trained and tested in a step-down inhibitory avoidance task (0.2-mA footshock; 48-h interval between sessions).

Animals received bilateral intra-amygdala $0.5-\mu$ infusions of vehicle ( $25 \%$ DMSO in saline) or CNQX $(0.5 \mu \mathrm{g}) 10 \mathrm{~min}$ prior to the test. $* \mathrm{P}<0.05$ for comparison between training and test session latencies by the Wilcoxon test. $+P<0.05$ for comparison between vehicle group and CNQX group by the Mann-Whitney test.

\begin{tabular}{|c|c|c|c|}
\hline \multirow[t]{2}{*}{ Group } & \multirow[t]{2}{*}{$\mathrm{N}$} & \multicolumn{2}{|c|}{ Latency to step-down (s) } \\
\hline & & Training & Test \\
\hline Vehicle & 11 & $4.42(3.15 / 12.75)$ & $21.51(11.13 / 126.16)^{*}$ \\
\hline CNQX & 10 & $3.42(2.00 / 5.71)$ & $8.07(6.39 / 13.92)^{*+}$ \\
\hline
\end{tabular}

Animals submitted to three training sessions significantly improved performance across consecutive sessions $(\mathrm{P}<0.01$, Friedman two-way analysis of variance) (Table 2). There were no differences in latencies between groups $(\mathrm{P}>0.10$, Mann-Whitney test). There were no significant differences between third training and test session latencies in any group $(\mathrm{P}>0.10$ for the vehicle group and $\mathrm{P}=0.09$ for the CNQX group, Wilcoxon test). The results suggest that intra-amygdala CNQX did not affect inhibitory avoidance retention in animals submitted to three training sessions. The findings of the present experiments indicate that additional training prevents the impairing effect of intra-amygdala infusion of CNQX given prior

Table 2 - Median (interquartile range) of latencies to step-down of rats submitted to three training and one test session (24-h interval between training sessions, 48-h interval between third training and test session) in a step-down inhibitory avoidance task (0.2-mA footshock).

Animals received bilateral intra-amygdala $0.5-\mu$ infusions of vehicle (25\% DMSO in saline) or CNQX (0.5 $\mu \mathrm{g})$ 10 min prior to the test. $* \mathrm{P}<0.01$ for comparison among consecutive sessions by Friedman two-way analysis of variance. There were no differences between groups ( $P>0.10$, Mann-Whitney test).

\begin{tabular}{lccccc}
\hline Group & $N$ & \multicolumn{4}{c}{ Latency to step-down (s) } \\
\cline { 3 - 6 } & & $\begin{array}{c}\text { 1st training } \\
\text { session }\end{array}$ & $\begin{array}{c}\text { 2nd training } \\
\text { session }\end{array}$ & $\begin{array}{c}\text { 3rd training } \\
\text { session }\end{array}$ & Test \\
\hline Vehicle & 13 & $3.31(1.99 / 5.65)$ & $64.13(23.89 / 160.50)$ & $300.00(227.59 / 300.00)$ & $300.00(53.00 / 300.00 * *$ \\
CNQX & 10 & $4.85(2.93 / 11.47)$ & $161.95(20.00 / 300.00)$ & $300.00(60.85 / 300.00)$ & $149.50(29.00 / 300.00)^{*}$
\end{tabular}


to test. Consistent with previous findings $(5,7,8)$, intra-amygdala CNQX attenuated, but did not block, inhibitory avoidance retention when given 10 min prior to test. This indicates that amygdaloid non-NMDA receptors are involved in retrieval of that task. However, the finding that additional training prevented the effect of CNQX suggests that non-NMDA receptor activation in the amygdala is not a critical mechanism of retrieval, and that the amygdala is not a critical site of storage and retrieval of fear-motivated memory. This is consistent with previous evidence that increased training attenuates the impairing effects of amygdaloid lesions (14) and intra-amygdala CNQX (15) on an aversively motivated escape training response.

In previous reports, increased training attenuated, but did not prevent, the effects of amygdala lesions and intra-amygdala CNQX, even in animals submitted to 10 or 20 training trials $(14,15)$. However, our results show that 3 training trials were sufficient to pre- vent the impairing effect of CNQX, as shown by the finding that CNQX-treated animals given 3 training trials had retention test latencies comparable to control animals given 3 training trials. It is possible that differences between tasks could explain this discrepancy. One interesting possibility is that an increased amount of training is more effective in preventing the effects of memoryimpairing treatments when trials are separated by a 24-h interval (present study) than when several trials are given consecutively in a single training session, as in previous studies $(14,15)$.

The major finding of the present report is that additional training prevents the impairing effect of intra-amygdala infusion of CNQX on retention of the step-down inhibitory avoidance task. This suggests that the amygdala participates in fear-motivated memory through a non-NMDA receptor-dependent mechanism as a modulatory site, rather than as a critical site for storage and retrieval.

\section{References}

1. Falls WA, Miserendino MJ D \& Davis M (1992). Extinction of fear-potentiated startle: blockade by infusion of an NMDA antagonist into the amygdala. J ournal of Neuroscience, 12: 854-863.

2. Kim J J, DeCola J P, Landeira-Fernandez J \& Fanselow MS (1991). N-methyl-D-aspartate receptor antagonist APV blocks acquisition but not expression of fear conditioning. Behavioral Neuroscience, 105: 160-167.

3. Kim M, Campeau S, Falls WA \& Davis M (1993). Infusion of the non-NMDA receptor antagonist CNQX into the amygdala blocks the expression of fear-potentiated startle. Behavioral and Neural Biology, 59: 5-8.

4. Miserendino MJ D, Sananes CB, Melia KR $\&$ Davis M (1990). Blocking of acquisition but not expression of conditioned fearpotentiated startle by NMDA antagonists in the amygdala. Nature, 345: 716-718.

5. Bianchin M, Walz R, Ruschel AC, Zanatta MS, DaSilva RC, Bueno e Silva M, Paczko N, Medina JH \& Izquierdo I (1993).
Memory expression is blocked by the infusion of CNQX into the hippocampus and/or the amygdala up to 20 days after training. Behavioral and Neural Biology, 59: 83-86.

6. Izquierdo I, Da Cunha C, Rosat R, J erusalinsky D, Ferreira MBC \& Medina J H (1992). Neurotransmitter receptors involved in memory processing by the amygdala, medial septum and hippocampus of rats. Behavioral and Neural Biology, 58: 16-25.

7. Izquierdo I, Bianchin M, Bueno e Silva M, Zanatta M, Walz R, Ruschel A, DaSilva RC, Paczko N \& M edina J H (1993). CNQX infused into rat hippocampus or amygdala disrupts the expression of memory of two different tasks. Behavioral and Neural Biology, 59: 1-4.

8. Izquierdo I, Quillfedt J A, Zanatta MS, Quevedo J, Schaeffer E, Schmitz PK \& Medina JH (1997). Sequential involvement of the hippocampus and amygdala, the entorhinal cortex, and the posterior parietal cortex in memory formation and retrieval. European J ournal of Neuroscience, 9: 786-793.

9. J erusalinsky $D$, Ferreira MBC, Walz R, DaSilva RC, Bianchin M, Ruschel AC, Zanatta MS, Medina JH \& Izquierdo I (1992). Amnesia by post-training infusion of glutamate receptor antagonists into the amygdala, hippocampus and entorhinal cortex. Behavioral and Neural Biology, 58: 76-80.

10. Bliss TVP \& Collingridge GL (1993). A synaptic model of memory: long-term potentiation in the hippocampus. Nature, 361: 31-39.

11. Kim M \& McGaugh J L (1992). Effects of intra-amygdala injections of NMDA receptor antagonists on acquisition and retention of inhibitory avoidance. Brain Research, 585: 35-48.

12. McGaugh J L, Cahill $L \&$ Roozendaal $B$ (1996). Involvement of the amygdala in memory storage: interaction with other brain systems. Proceedings of the $\mathrm{Na}$ tional Academy of Sciences, USA, 93: 13508-13514. 
13. Cahill L \& McGaugh J L (1990). Amygdaloid complex lesions differentially affect retention of tasks using appetitive and aversive reinforcement. Behavioral Neuroscience, 104: 532-543.

14. Parent M, Tomaz C \& M CGaugh J L (1992). Increased training in an aversively moti- vated task attenuates the memory-impairing effects of posttraining N-methyl-D-aspartate-induced lesions. Behavioral Neuroscience, 106: 789-797.

15. Mesches $M H$, Bianchin M \& McGaugh J L (1996). The effects of intra-amygdala infusion of the AMPA receptor antagonist
CNQX on retention performance following aversive training. Neurobiology of Learning and Memory, 66: 324-340.

16. Paxinos G \& Watson C (1986). The Rat Brain in Stereotaxic Coordinates. 2nd edn. Academic Press, San Diego. 